${ }^{1}$ Department of Endodontics, Faculty of Dentistry, University of Bolu Abant Izzet Baysal, Bolu, Turkey

${ }^{2}$ Department of Biostatistics, Faculty of Medicine, Tokat Gaziosmanpasa University, Tokat, Turkey
Corresponding author: Hakan Gokturk, Department of Endodontics, Faculty of Dentistry, Abant Izzet Baysal University, Bolu, Turkey, 14100 Phone: +90-374-2705353 ext-8453 Fax: +90-374 2700066 e-mail: gokturk82@hotmail.com

Received: March 20, 2019

Accepted: September 19, 2019

\section{Evaluation of the dislodgement resistance of bioceramic reparative cements placed in a retrograde cavity using a different technique}

\author{
Hakan Gokturk, ${ }^{1,}$, Ismail Ozkocak ${ }^{1}$, Seda Tan-Ipek ${ }^{1}$ \\ Osman Demir ${ }^{2}$
}

Aim: Calcium silicate-based fillings have been widely used in surgical endodontic treatment because of hard-tissue conductive and inductive properties. The aim of present study is to investigate the bond strength of different calcium silicate-based fillings in retrograde cavities. Methods: Forty-four maxillary single rooted teeth were endodontically treated. The apical portions of the teeth were removed and root-end cavities were prepared using an ultrasonic tip. The roots were randomly divided into four experimental groups $(n=11)$ according to the material used; (1) MTA-FILLAPEX, (2) MTA Repair HP, (3) MTA-FILLAPEX+ MTA Repair HP, and (4) MTA Plus. Two horizontal cross sections ( $1 \pm 0.1 \mathrm{~mm}$ thick) from each specimen were resected from the apices. These sections were placed in a universal testing machine to evaluate the push-out bond strength force required for dislodgement of the root end filling was recorded. The failure type was also evaluated by using a stereomicroscope. The differences in bond strength were analyzed using the two-way analysis of variance (ANOVA). Results: MTA-FILLAPEX and MTA Plus displayed the lowest and highest dislocation resistance, respectively $(P<0.05)$. In the apical level, bond strength was significantly higher than the coronal level in all groups except for MTA-FILLAPEX. Mixed failure was prevalent in all groups, except for MTA-FILLAPEX which showed purely cohesive failures. Conclusions: Investigated calcium silicate-based filling materials showed different bond strength to the root-end cavity. The bond strength was significantly decreased when the prior application of MTA-FILLAPEX before delivery of MTA Repair HP.

Keywords: Calcium compounds. Silicates. Root canal filling materials. Retrograde obturation. Endodontics. 


\section{Introduction}

In cases of orthograde root canal treatment failures or presence of persistent periradicular lesion, endodontic surgery is recommended. The aim of endodontic surgery is to remove periradicular lesion and irritants, 3-dimensional sealing of the retrograde cavity. Hermetic sealing of retrograde cavities in 3-dimensions with biocompatible materials is crucial for the success of endodontic surgery ${ }^{1,2}$. Mineral trioxide aggregate (MTA) is one of the most used root-end filling material because of its superior sealing ability, antibacterial properties, biocompatibility, hard-tissue conductive and inductive properties and set in the presence of blood and moisture ${ }^{3,4}$. Also, MTA promotes the accumulation of calcium and phosphate crystals into the gaps between the filling material and dentin ${ }^{5}$. However, the slow setting time of MTA is problematic especially when it used in the endodontic surgery because of the possibility of washout from the root-end cavity during irrigation ${ }^{2,6,7}$. Another common drawbacks of MTA are difficulties in handling and manipulation?

MTA Plus (Prevest Denpro Limited, Jammu, India) is another calcium silicate-based material which is composed of tricalcium and dicalcium silicate, calcium sulfate, silica, and bismuth oxide. Bismuth oxide is the most used radiopacifying agent in traditional MTA. It plays a crucial role in the hydration processes of calcium silicate ${ }^{8}$. However, it responsible for tooth discoloration especially when it contacts with sodium hypochlorite ${ }^{9}$. According to manufacture the particle size of MTA Plus is smaller than MTA that improves its manipulation and handling characteristics ${ }^{10}$.

MTA Repair HP (Angelus, Londrina, PR, Brazil) is another newly formulated MTA based material which is composed of calcium oxide, dicalcium silicate, tricalcium aluminate, tricalcium silicate, and calcium tungstate as radiopacifier. The plasticizer in the liquid facilitates manipulation and handling of material. Also, this material has the same biological effects as the traditional MTA ${ }^{11}$.

MTA-FILLAPEX (Angelus, Brazil) is a bioceramic root canal sealer based on MTA, composed of salicylate resin, natural resin, diluting resin, MTA, nanoparticulated silica, and calcium tungstate as radiopacifier. When the set MTA comes into contact with simulated body fluids, hydroxyl and calcium ions released from the material encourage the formation of calcium phosphates. In previous studies, MTA- FILLAPEX displayed lower push-out bond strength to root dentin than AH Plus and iRoots SP12,13. The reason for this situation was attributed to the low adhesion capacity of tag-like structures which is produced within collagen fibrils ${ }^{13}$.

Adequate adhesion of the root-end filling material to the dentin is important to prevent the leakage which is critical for the long-term success of the endodontic surgery ${ }^{14}$. Push-out testing is the most suitable test for evaluating the bond strength and the dislocation resistance of dental materials to root dentin. Maximum bond strength of retrograde filling materials minimizes the consist of displacement that may cause voids and cracks, resulting in failure of endodontic surgery ${ }^{15}$.

The aim of this study is to investigate the bond strength of various calcium silicate-based filling materials in retrograde cavities. MTA Plus was used as the reference material for comparison. The null hypothesis is that there will be no difference in the dislocation resistance between the investigated filling materials. 


\section{Material and Methods}

\section{Sample size calculation}

A priori power analysis was performed to determine adequate number of samples to be included in the study. An effect size of 0.40 was added to a power $b=87 \%$ and $a=5 \%$ input into an $\mathrm{F}$ test family for analysis of variance, we needed 88 samples for four groups.

\section{Sample selection and preparation}

After Ethics Committee approval (2018/36), 44 human, single-rooted teeth with single root canal were immersed in $1 \%$ thymol solution until they were used. A periodontal scaler was used to remove soft tissue and calculus from the root surfaces. Then all teeth were examined under stereoscopic at $\times 25$ magnification and teeth with free of root caries, fractures, resorption, calcifications and previous endodontic treatment were included. The included teeth were radiographed mesiodistally and buccolingually to confirm a single canal and other inclusion criteria. The coronal portion was removed under copious water irrigation with a diamond disc to obtain roots of $15 \mathrm{~mm}$ length. The working length was determined by using a K-file (VDW, Munich, Germany) which inserted into the root canal until it was visible at the apex. The working length was determined to be $1 \mathrm{~mm}$ short of this point. The root canals were shaped using Reciproc rotary files (VDW) till size R40 according to the manufacturer's instructions. After three pecking motions, $2 \mathrm{~mL}$ of $5.25 \% \mathrm{NaOCl}$ solution was used for irrigation. Five $\mathrm{mL}$ of $17 \%$ EDTA (Imicryl Ltd., Konya, Turkey) was used to remove the smear layer for $1 \mathrm{~min}$. The prepared canals were dried with paper points and filled with cold lateral compaction of gutta-percha and an epoxy-resin based sealer (2seal, VDW, Munchen, Germany). The access of canals was filled with Cavit (ESPE, Seefeld, Germany) and the roots were kept at $37^{\circ} \mathrm{C}$ in $100 \%$ humidity for 14 days.

A $3 \mathrm{~mm}$ section of the apical part of the root was removed at 90 to the longitudinal axis of the teeth with a diamond bur using a high-speed handpiece under copious irrigation with saline (Figure 1A). A retrograde cavity of $3 \mathrm{~mm}$ depth was prepared with ultrasonic retro tips (AS3D, Satelec Acteon Group, Merignac cedex, France) coupled to the file holding adapter of a Satelec P5 Newtron XS ultrasonic system handpiece (Satelec Acteon Group, France) at power setting 5 under copious irrigation with saline. The handpiece and sample were fixed on a device used to favor parallelism of the dentin walls. To obtain standard root-end cavity, residual gutta-percha was removed with a probe and the dimensions of the cavity were checked with a periodontal probe.
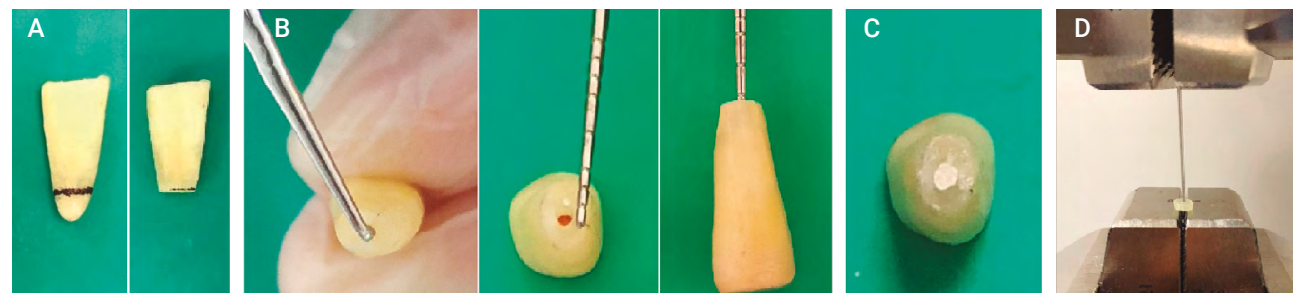

Figure 1. (A) Resected root sample. (B) Root-end cavity preparation and control of dimensions. (C) Root-end cavity filled sample. (D) Push-out bond strength test of $1 \mathrm{~mm}$ cross sections sample. 
The dimensions of the retrograde cavity were approximately $1.5 \mathrm{~mm}$ diameter and 3 $\mathrm{mm}$ deep (Figure 1B). The preparation time was approximately $35 \mathrm{~s}$. The cavities were dried with paper points. The samples were randomly divided into 4 groups based on root-end filling material ( $n=11$ per group) as follows; MTA-FILLAPEX, MTA Repair HP, MTA-FILLAPEX+MTA Repair HP, and MTA Plus. The materials were prepared according to the manufacturers.

Group 1 (MTA-FILLAPEX); An equal portion of base and catalyst paste (1:1 ratio) was mixed for $30 \mathrm{~s}$ to obtain homogeneous consistency. The mixed sealer was transported into a cleaned acid etching syringe with a Luer Lock-type delivery tip. The first $3 \mathrm{~mm}$ of the delivery tip was bent $90^{\circ}$ and the suitability to retro-cavity was checked without excessive binding before use. The sealer was injected from the deep of the retro-cavity to the root end to avoid any voids.

Group 2 (MTA Repair HP); One package of MTA Repair HP powder (85 mg) and 2 drops of the liquid was mixed on the glass slap for $40 \mathrm{~s}$ to obtain a homogeneous mixture. A microcarrier was used to place the cement into the retro-cavity and a matching hand plugger was used to compact it.

Group 3 (MTA-FILLAPEX +MTA Repair HP); Retro-cavities filled with MTA-FILLAPEX as in group 1 were then filled with MTA Repair HP as in group 2.

Group 4 (MTA Plus); According to the manufacturer; a 1:3 liquid: powder ratio by weight was mixed on a glass for $30 \mathrm{~s}$ to obtain a homogeneous consistency. A microcarrier was used to place the cement into the retro-cavity and a fitted hand plugger was used to compact it (Figure 1C).

Excess materials on the resected root surface were removed with a microbrush and a plastic instrument. A radiograph was taken to confirm the quality of filling from all samples. All procedures were carried out by one endodontist who has seven years of clinical experience.

After root-end filling procedures, the specimens were immersed in $8 \mathrm{~mL}$ of $\mathrm{Mg}$ - and Ca- free phosphate-buffered saline solution (PBS, $\mathrm{pH}=7.2$ ) at $37^{\circ} \mathrm{C}$ for 14 days. PBS was renewed at 3 days intervals.

\section{Push-out Bond Strength Test}

Following the restoration of root-end cavities two horizontal cross sections $(1 \pm 0.1 \mathrm{~mm}$ thick) from each specimen ( $n=22$ slices/group) was created, from the apico-coronal direction, using a low-speed saw (ISOMET; Buehler Ltd, Lake Bluff, USA) with a water cooled diamond disc. The thickness of each section was controlled using a digital caliper (Macrona, Simetri Teknik, Izmir, Turkey) at an accuracy of $0.001 \mathrm{~mm}$. The coronal and apical diameters of each root-end filling material were measured under a stereomicroscope (×20-30 magnification).

The push-out test was performed using a mechanical testing machine (AGS-X, Shimadzu, Kyoto, Japan) with a load of $5 \mathrm{kN}$ operating at $1 \mathrm{~mm} / \mathrm{min}$ crosshead speed until dislodgement of the filling material occurred. The push-out force was applied from the coronal to apical the direction with a stainless steel plugger which its diameter covered the $90 \%$ of the diameter of the root-end filling material on the coronal 
surface without coming into contact with the surrounding dentin (Figure 1D). The dislocation resistance value at failure in megapascals (MPa) was calculated from the maximum push-out force $(\mathrm{N})$ divided by bonding surface area $(\mathrm{mm})$. The bonding surface area (SA) for each slice was calculated according to the following formula: $S A=$, = 3.14; means the thickness of each root disc $(1 \mathrm{~mm})$, is coronal radius or the smaller radius of the canal width, and is apical radius or the larger radius of the canal width.

The failure modes of each slide were assessed under a stereomicroscope at $\times 40$ magnification and classified into one of the three following categories: (1) cohesive failure inside the root-end filling, (2) adhesive failure between root-end filling and dentin, (3) mixed failure which is a combination of both.

All statistical analyses were performed by using SPSS software (IBM SPSS Statistics 19, SPSS Inc., IBM Co., Somers, New York, USA). Two-way analysis of variance (ANOVA) and the post hoc Bonferroni test was used to analyze the differences of the data with a 0.05 level of significance.

\section{Results}

Table 1 shows the mean and standard deviations of the bond strength for each group. No premature failure was observed (occurred) and all the specimens showed measurable debonding values. Statistically significant differences were observed in the dislocation resistance of the retrograde filling materials regardless of the root regions $(p<0.05)$. The highest and lowest dislocation resistance was obtained for the MTA Plus (14.97 \pm 2.13$)$ and the MTA-FILLAPEX $(0.41 \pm 0.09)$, respectively $(p<0.05)$. A statistically significant ranking for dislocation resistance values was obtained as follows: MTA Plus >MTA Repair HP >MTA-FILLAPEX +MTA Repair HP >MTA-FILLAPEX $(p<0.05)$.

A significant difference between each group in both regions were identified $(p<0.05)$, except for group 1 and 3 at the coronal region $(p>0.05)$. A statistically significant ranking for dislocation resistance values at apical and coronal level was obtained as follows: MTA Plus >MTA Repair HP > MTA-FILLAPEX + MTA Repair HP > MTA-FILLAPEX and MTA Plus >MTA Repair HP > MTA-FILLAPEX + MTA Repair HP $\geq$ MTA-FILLAPEX, respectively $(p<0.05)$.

Comparisons in terms of root regions revealed that the highest values were observed in the apical level of the all groups, but this difference was statistically significant for all investigated materials except for MTA-FILLAPEX $(p<0.05)$.

Table 1 . The push out bond strength (MPa, mean \pm standard deviation) of root filling materials in different root regions.

\begin{tabular}{lcccc}
\hline \multirow{2}{*}{ Material } & \multicolumn{2}{c}{ Region } & \multirow{2}{*}{$\boldsymbol{P}$ value } & \multirow{2}{*}{ Total } \\
\cline { 2 - 5 } & \multicolumn{1}{c}{ Apical } & Coronal & & \\
\hline MTA-FILLAPEX & $0.55 \pm 0.10^{\mathrm{a}, \mathrm{A}}$ & $0.41 \pm 0.09^{\mathrm{a}, \mathrm{A}}$ & 0.746 & $0.48 \pm 0.12^{\mathrm{a}}$ \\
\hline MTA Repair HP & $7.21 \pm 0.93^{\mathrm{b}, \mathrm{A}}$ & $6.35 \pm 0.98^{\mathrm{b}, \mathrm{B}}$ & 0.048 & $6.78 \pm 1.03^{\mathrm{b}}$ \\
\hline MTA-FILLAPEX +MTA Repair HP & $2.38 \pm 0.29^{\mathrm{c}, \mathrm{A}}$ & $1.06 \pm 0.14^{\mathrm{a}, \mathrm{B}}$ & 0.003 & $1.72^{\mathrm{a}} \pm 0.72^{\mathrm{c}}$ \\
\hline MTA Plus & $14.97 \pm 2.13^{\mathrm{d}, \mathrm{A}}$ & $13.28 \pm 1.22^{\mathrm{c}, \mathrm{B}}$ & $<0.001$ & $14.12 \pm 1.90^{\mathrm{d}}$ \\
\hline$P$ value & $<0.001$ & $<0.001$ & & $<0.001$ \\
\hline
\end{tabular}

Two-way ANOVA was used. Lowercase letters indicate comparison among materials in column; uppercase letters indicate comparison among region in row. Different letters indicate significance of the difference at a $P<0.05$. 
Failure modes are shown in Figure 2. In all investigated materials expect for MTA-FILLAPEX, most common mode of failure was mixed failure, which means the presence of adhesive and cohesive failures at the same slice. MTA-FILLAPEX displayed purely cohesive failure in all samples. Adhesive failure was seen only in the MTA Plus among all investigated materials.

\section{Discussion}

In previous studies, it was reported that if a root canal filling material chemically bonds to root dentin, it resists the dislocation forces and improves the push-out bond strength of materials and contributes to the longevity and prognosis of endodontically treated teeth ${ }^{15-17}$. This study investigated the dislodgement resistance of different root-end filling materials to root canal dentin. In the light of the results of the present study, all investigated retrograde filling materials showed different dislocation resistance. Therefore, the null hypothesis which there is no difference in the dislocation resistance between the investigated filling materials was rejected. Also, the use of MTA-FILLAPEX to coat the root-end cavity walls before obturation with MTA Repair HP displayed a decrease in the push-out bond strength of MTA Repair HP.

The push-out test is a reliable, easy, and widely used technique to investigate the bond strength of root canal filling materials and posts to the root dentin. The push-out strength - also called dislodgement resistance defines the resistance to dislocation of materials applied to dental hard tissues. Improved dislodgement resistance indicates that the material has good adhesion ability and represents the longevity of the restoration. The push-out test allows many sub-samples (or sections) to be taken from a sample ${ }^{12,13,18-20}$. Soares et al. ${ }^{18}$ reported that the push-out test produces less variability and a more homogenous stress distribution than the microtensile bond test during dislocation resistance testing applied to intraradicular dentin. However, a recently published systematic review with meta-analysis demonstrated that some method-

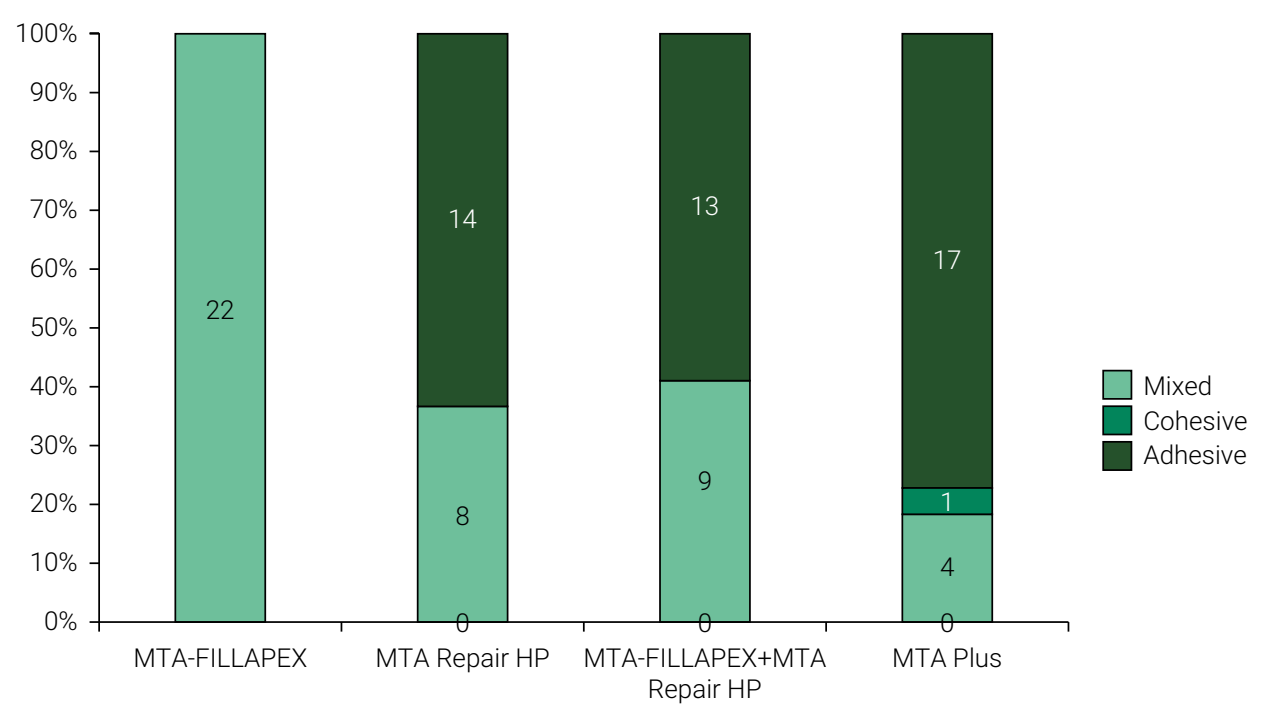

Figure 2. Number and percentage of failure modes in each investigated groups. 
ological variables such as tooth portion, storage time, slice thickness, obturation technique, punch diameter, and load velocity influence the resistance to dislodgment of material ${ }^{21}$. Similarly, storage environment (distilled water or PBS) influenced the dislocation resistance of the materials from retrograde cavities ${ }^{22}$. These variables may cause restrictions on the comparison of different study results. According to previous studies' reports, in order to standardize all variables, $1 \pm 0.1 \mathrm{~mm}$ thickness slices ${ }^{21}$, and a plugger which cover at least $90 \%$ of the canal width ${ }^{19}$ should be used. All samples were stored in PBS to simulate clinical conditions ${ }^{23}$ in this study.

Ultrasonic tips, drills, and lasers have been used to prepare root-end cavities $20,22,24,25$ The use of ultrasonic tips allows obtaining parallel walls with improving retention for filling material and provides obtain deeper, cleaner, and more centered cavities with less opening of dentin tubules ${ }^{24,25}$. Ultrasonic tips with different designs and angles facilitate the preparation of the root-end cavity at the posterior teeth. All of them have contributed to the increase in the success rate of periapical surgery'. Thus, in this in vitro study, diamond ultrasonic tips (AS3D, Satelec Acteon Group, France) were chosen to prepare the root-end cavities.

MTA-FILLAPEX composition is based on bioceramic materials which containing MTA and resins. In a study, it was observed that when the set sealer contacts with phosphate-containing fluids it release calcium and hydroxyl ions and it creates apatite crystals. It was showed that created apatite produced by PBS and MTA precipitate within collagen fibrils, promoting controlled mineral nucleation on dentin and this situation results in the formation of an interfacial layer with tag-like structures ${ }^{26}$. The results of the present study showed it has significantly lower bond strength values $(0.48 \pm 0.12 \mathrm{MPa})$ than the other investigated materials. The obtained results may be explained by the low adhesion capacity of MTA-FILLAPEX due to the aforementioned interfacial layer. These results are in agreement with the results reported by Sagsen et al. ${ }^{13}$ who reported that the bond strength of MTA-FILLAPEX to root dentine was lower than i Root SP and AH Plus. Another explanation of low adhesion of MTA-FILLAPEX is related with the existing of smear layer on the dentin surface ${ }^{27}$.

MTA Repair HP is a recently introduced MTA-based material to improve physical properties of traditional MTA. According to the manufacturer it is recommended for use as pulpotomy, pulp capping, apexification, apexogenesis, root-end filling, and to repair resorption and perforations. It contains calcium tungstate as a radiopacifier. Calcium tungstate also prevents dental discoloration caused by bismuth oxide. Silva et al. ${ }^{23}$ report that calcium tungstate contributes to higher calcium release, promoting higher biomineralization, and result in MTA Repair HP displayed higher dislocation resistance compared to White MTA. However, in the present study MTA Repair HP, which containing calcium tungstate, showed significantly lower bond strength than MTA Plus, which containing bismuth oxide. This difference may be related to the small particle size of the MTA plus.

MTA Plus has a finer particle size (50\% of the particles/power thinner than $1 \mu \mathrm{m}$.) compared to traditional MTA, which improves its handling characteristics and may increase the speed of hydration process. MTA Plus powder is mixed with water or gel. In a previous study, MTA Plus mixed with water, chemically curing resin, antiwashout gel, and light-curing resin. Investigators have reported that MTA Plus mixed with water had higher bond 
strength than the one mixed with ge ${ }^{20}$. In another study, MTA Plus mixed with polymer gel showed significantly lower bond strength than MTA and Biodentine in furcal perforation areas after a setting time of seven days ${ }^{28}$. Consistent with the aforementioned study results, the present study showed that the MTA Plus represented a higher dislocation resistance than other investigated retrograde filling materials when mixed with water.

Following endodontic surgery, root-end filling materials contact directly with blood. However, the use of blood in in vitro studies during the setting time of cement is not possible. Usually, the samples were stored at $100 \%$ humidity environment, in a PBS $^{22,23}$ deionized water ${ }^{22}$ or Hanks' Balanced Salt Solution ${ }^{5,20}$. Results of the previous studies, demonstrated that the contact of calcium silicate containing materials with phosphate-based solutions results in the formation of apatite-like structures at the dentin-material interface and promote the formation of tag-like structures ${ }^{26}$, which subsequently result in improved dislocation resistance ${ }^{22}$ sealing ability by decreasing the interface voids ${ }^{5}$. In the present study, the resected root samples were stored in PBS to promote a condition closer to a clinical condition.

Regarding the type of failure, mixed failure was predominated, in accordance with the results of the previous studies ${ }^{20,29}$ which means failure is related with not only in the bond with the radicular dentin (adhesive failures) but also the material itself (cohesive failures). In line with the presented study results, Formosa et al. ${ }^{20}$ comparing the bond strength of MTA Plus which was mixed with different liquids (light-curing resin, chemical curing resin, antiwashout gel, distilled water) have found failure was significantly higher in the distilled water mixing group. MTA-FILLAPEX which was investigated in the present study showed cohesive failure in all samples. Because of MTA-FILLAPEX is a sealer, its consistency is more fluid than the other investigated filling materials. The lack of consistency may have caused more ion release during the setting period. This situation as stated in previous studies ${ }^{29,30}$ results in an uneven and porous microstructure, which disrupts the material structure and prevents material cohesion, and may be the cause of excess cohesive failure observed in the present study.

To the best of our knowledge, studies evaluating the effect of the prior application of endodontic sealer on the bond strength of retrograde material to root-end cavity wall are limited. In a recent study, the marginal adaptation of BC RRM-Fast Set Putty, and BC Sealer + BC RRM-Fast Set Putty was investigated after orthograde placement in teeth with open apices. The authors reported that the gap size in the root-end filling was significantly smaller when prior use of BC Sealer before application of BC RRMFast Set Putty ${ }^{31}$. However, in the present study, the gap size in the root-end filling was not investigated, only bond strength was compared. So, these results could not be compared with those of the aforementioned study results.

The investigated filling materials in this study showed different dislodgement resistance to the root-end cavity. Prior application of MTA-FILLAPEX before delivery of MTA Repair HP, decreased the bond strength of MTA Repair HP.

\section{Acknowledgements}

The authors declare that they have no conflict of interests. This study was not supported by any foundation. 


\section{References}

1. Kim S, Kratchman S. Modern endodontic surgery concepts and practice: a review. J Endod. 2006 Jul;32(7):601-23.

2. Porter ML, Berto A, Primus CM, Watanabe I. Physical and chemical properties of new-generation endodontic materials. J Endod. 2010 Mar;36(3):524-8. doi:10.1016/j.joen.2009.11.012.

3. Parirokh M, Torabinejad M. Mineral trioxide aggregate: a comprehensive literature review--Part I: chemical, physical, and antibacterial properties. J Endod. 2010 Jan;36(1):16-27. doi: 10.1016/j.joen.2009.09.006

4. Torabinejad M, Parirokh M. Mineral trioxide aggregate: a comprehensive literature review-part II: leakage and biocompatibility investigations. J Endod. 2010 Feb;36(2):190-202. doi: 10.1016/j.joen.2009.09.010.

5. Gandolfi M, Parrilli A, Fini M, Prati C, Dummer PMH. 3 D micro-CT analysis of the interface voids associated with T hermafil root fillings used with AH Plus or a flowable MTA sealer. Int Endod J. 2013 Mar;46(3):253-63. doi: 10.1111/j.1365-2591.2012.02124.x.

6. Kogan P, He J, Glickman GN, Watanabe I. The effects of various additives on setting properties of MTA. J Endod. 2006 Jun;32(6):569-72.

7. Torabinejad M, Hong C, McDonald F, Ford TP. Physical and chemical properties of a new root-end filling material. J Endod. 1995 Jul;21(7):349-53.

8. Camilleri J. Characterization of hydration products of mineral trioxide aggregate. Int J Endod. 2008 May;41(5):408-17. doi: 10.1111/j.1365-2591.2007.01370.x.

9. Camilleri J. Color stability of white mineral trioxide aggregate in contact with hypochlorite solution. J Endod. 2014 Mar;40(3):436-40. doi: 10.1016/j.joen.2013.09.040.

10. Govindaraju L, Neelakantan P, Gutmann JL. Effect of root canal irrigating solutions on the compressive strength of tricalcium silicate cements. Clin Oral Investig. 2017 Mar;21(2):567-571. doi: 10.1007/s00784-016-1922-0.

11. Guimaraes BM, Prati C, Duarte MAH, Bramante CM, Gandolfi MG. Physicochemical properties of calcium silicate-based formulations MTA Repair HP and MTA Vitalcem. J Appl Oral Sci. 2018 Apr;26:e2017115. doi: 10.1590/1678-7757-2017-0115

12. Nagas E, Cehreli Z, Uyanik MO, Durmaz V. Bond strength of a calcium silicate-based sealer tested in bulk or with different main core materials. Braz Oral Res. 2014; 28. pii: S1806-83242014000100256.

13. Sagsen B, Ustün Y, Demirbuga S, Pala K. Push-out bond strength of two new calcium silicate-based endodontic sealers to root canal dentine. Int Endod J. 2011 Dec;44(12):1088-91. doi: 10.1111/j.1365-2591.2011.01925.x.

14. Abdal AK, Retief DH. The apical seal via the retrosurgical approach: I. A preliminary study. Oral Surg Oral Med Oral Pathol. 1982 Jun;53(6):614-21.

15. Vivan RR, Guerreiro-Tanomaru JM, Bernardes RA, Reis JMSN, Duarte MAH, Tanomaru-Filho M. Effect of ultrasonic tip and root-end filling material on bond strength. Clin Oral Investig. 2016 Nov;20(8):2007-11.

16. Onay EO, Ungor M, Ari H, Belli S, Ogus E. Push-out bond strength and SEM evaluation of new polymeric root canal fillings. Oral Surg Oral Med Oral Pathol Oral Radiol Endod. 2009 Jun;107(6):879-85. doi: 10.1016/j.tripleo.2009.01.023.

17. Huffman B, Mai S, Pinna L, Weller R, Primus C, Gutmann J, et al. Dislocation resistance of ProRoot Endo Sealer, a calcium silicate-based root canal sealer, from radicular dentine. Int Endod J. 2009 Jan;42(1):34-46. doi: 10.1111/j.1365-2591.2008.01490.x.

18. Soares CJ, Santana FR, Castro CG, Santos-Filho PC, Soares PV, Qian F, et al. Finite element analysis and bond strength of a glass post to intraradicular dentin: comparison between microtensile and push-out tests. Dent Mater. 2008 Oct;24(10):1405-11. doi:10.1016/j.odontológico.2008.03.004. 
19. Pane ES, Palamara JE, Messer HH. Critical evaluation of the push-out test for root canal filling materials. J Endod. 2013 May;39(5):669-73. doi: 10.1016/j.joen.2012.12.032.

20. Formosa L, Mallia B, Camilleri J. Push-out bond strength of MTA with antiwashout gel or resins. Int Endod J. 2014 May;47(5):454-62. doi: 10.1111/iej.12169.

21. Collares F, Portella F, Rodrigues S, Celeste R, Leitune V, Samuel S. The influence of methodological variables on the push-out resistance to dislodgement of root filling materials: a meta-regression analysis. Int Endod J. 2016 Sep;49(9):836-49. doi: 10.1111/iej.12539.

22. do Carmo S, Néspoli F, Bachmann L, Miranda C, Castro-Raucci L, Oliveira I, et al. Influence of early mineral deposits of silicate-and aluminate-based cements on push-out bond strength to root dentine. Int Endod J. 2018 Jan;51(1):92-101. doi: 10.1111/iej.12791.

23. Silva EJ, Carvalho NK, Zanon M, Senna PM, De-Deus G, Zuolo ML, et al. Push-out bond strength of MTA HP, a new high-plasticity calcium silicate-based cement. Braz Oral Res. 2016 Jun 14;30(1). pii: S1806-83242016000100269. doi: 10.1590/1807-3107BOR-2016.vol30.0084.

24. Wuchenich G, Meadows D, Torabinejad M. A comparison between two root end preparation techniques in human cadavers. J Endod. 1994 Jun;20(6):279-82.

25. de Faria-Junior NB, Tanomaru-Filho M, Guerreiro-Tanomaru JM, de Toledo Leonardo R, Berbert FLCV. Evaluation of ultrasonic and ErCr: YSGG laser retrograde cavity preparation. J Endod. 2009 May;35(5):741-4. doi: 10.1016/j.joen.2009.02.007

26. Reyes-Carmona JF, Felippe MS, Felippe WT. A phosphate-buffered saline intracanal dressing improves the biomineralization ability of mineral trioxide aggregate apical plugs. J Endod. 2010 Oct;36(10):1648-52. doi: 10.1016/j.joen.2010.06.014.

27. Reyhani MF, Ghasemi N, Rahimi S, Milani AS, Mokhtari H, Shakouie S, et al. Push-out bond strength of Dorifill, Epiphany and MTA-Fillapex sealers to root canal dentin with and without smear layer. Iran Endod J. 2014 Fall;9(4):246-50.

28. Aggarwal V, Singla M, Miglani S, Kohli S. Comparative evaluation of push-out bond strength of ProRoot MTA, Biodentine, and MTA Plus in furcation perforation repair. J Conserv Dent. Sep. 2013; 16 (5): 462-5. doi: 10.4103 / 0972-0707.117504.

29. Stefaneli Marques JH, Silva-Sousa YTC, Rached-Júnior FJA, Macedo LMDd, Mazzi-Chaves JF, Camilleri J, et al. Push-out bond strength of different tricalcium silicate-based filling materials to root dentin. Braz Oral Res. 2018 Mar;32:e18. doi: 10.1590/1807-3107bor-2018.vol32.0018.

30. Borges R, Sousa-Neto M, Versiani M, Rached-Júnior F, De-Deus G, Miranda C, et al. Changes in the surface of four calcium silicate-containing endodontic materials and an epoxy resin-based sealer after a solubility test. Int Endod J. 2012 May;45(5):419-28. doi: 10.1111/j.1365-2591.2011.01992.x.

31. Tran D, He J, Glickman GN, Woodmansey KF. Comparative Analysis of Calcium Silicate-based Root Filling Materials Using an Open Apex Model. J Endod. 2016 Apr;42(4):654-8. doi: 10.1016/j.joen.2016.01.015. 